Research, Society and Development, v. 9, n. 12, e14491210945, 2020

(CC BY 4.0) | ISSN 2525-3409 | DOI: http://dx.doi.org/10.33448/rsd-v9i12.10945

\title{
Ensino-aprendizagem de geografia em tempos de pandemia: relato e discussão sobre estratégias adotadas no Ensino Remoto Emergencial
}

Teaching-learning geography in pandemic times: report and discussion on strategies adopted in Emergency Remote Teaching

Enseñanza-aprendizaje de geografia en tiempos de pandemia: informe y discussión de estratégias adoptadas en la Enseñanza Remota de Emergencia

Recebido: 06/12/2020 | Revisado: 14/12/2020 | Aceito: 14/12/2020 | Publicado: 15/12/2020

\section{Paulo Eduardo Alves Borges da Silva}

ORCID: https://orcid.org/0000-0003-4954-2188 Instituto Federal de Educação, Ciência e Tecnologia de Educação, Brasil

E-mail: borges.paulo@ifmg.edu.br

Malena Silva Nunes

ORCID: https://orcid.org/0000-0002-2868-1376

Centro Federal de Educação Tecnológica de Minas Gerais, Brasil

E-mail: malenanunes@cefetmg.br

\section{Resumo}

Este trabalho consiste em um relato de experiência da vivência profissional em lecionar o conteúdo da disciplina de Geografia para alunos do Ensino Técnico Integrado do Instituto Federal de Educação, Ciência e Tecnologia de Minas Gerais - campus Betim, diante do cenário emergencial de adoção de um ensino remoto emergencial, majoritariamente via Tecnologias Digitais de Informação e Comunicação (TDICs). São apresentados conceitos e teorias relacionados à educação, ao ensino, à relação ensino-aprendizagem que embasam discussões relacionadas às diferentes possibilidades de métodos de ensino e estilos de aprendizagem. Tal alicerce subsidia os exemplos apresentados, que foram distribuídos via Ambiente Virtual de Aprendizagem (AVA). Assim, o objetivo deste relato é apresentar e discutir as estratégias adotadas em aulas e atividades avaliativas. Observa-se que, dado o caráter excepcional do ano de 2020, de pandemia e ensino remoto, foi possível manter relações importantes, como a professor-aluno e a escola-aluno. Além disso, é possível afirmar que a variação nos métodos de ensino propiciou engajamento, interesse e envolvimento dos alunos, o que ficou evidenciado pela participação nas aulas síncronas e pelos comentários 
após o cumprimento de atividades. Dessa maneira, o que seria uma possibilidade emergencial para o contexto de ensino atual tornou-se uma ferramenta importante quando da retomada das atividades presenciais.

Palavras-chave: Geografia; Ensino Remoto; Ensino-Aprendizagem.

\section{Abstract}

This paper consists of an experience report of the professional experience in teaching the contente of the Geography to students of the Integrated Technical Teaching of the Federal Institute od Education, Science and Technology of Minas Gerais - campus Betim, in the face of the emergency scenario of adopting a teaching emergency remote control, mostly via Digital Information and Communication Technologies (DICTs). Concepts and theories related to education, teaching and the teaching-learning relationship are presented that support discussions related to the diferente possibilities of teaching methods and learnig styles. This foundation supports the examples presented, which were distributed via the Virtual Learning Environment (VLE). Thus, the purpose of this repor tis to present and discuss the strategies adopted in classes and evaluative activities. It is observed that, given the exceptional character of the year 2020, pandemic and remote education, it was possible to maintain importante relationships, such as teacher-student and school-student. In addition, it is possible to affirm that the variation in the teaching methods provided engagement, interest and involvement of the students, which was evidenced by the participation in the synchronous classes and by the comments after the fulfillment of activities. In this way, what would be an emergency possibility for the current teaching contexto has become an importante tool when resuming face-to-face activities.

Keywords: Geography; Remote Teaching; Teaching-Learning.

\section{Resumen}

Este trabajo consiste en un relato de la experiencia profesional en la enseñanza del contenido de Geografía a estudiantes de la Docencia Técnica Integrada del Instituto Federal de Educación, Ciencia y Tecnología de Minas Gerais - campus Betim, ante el escenario de emergencia de adoptar una enseñanza remota de emergencia, principalmente a través de Tecnologías de Información y Comunicación Digitales (TICDs). Se presentan conceptos y teorías relacionados con la educación, la enseñanza y la relación enseñanza-aprendizaje que sustentan discusiones relacionadas com las diferentes posibilidades de métodos de enseñanza y estilos de aprendizaje. Esta base respalda los ejemplos presentados, que se distribuyeron a 
través del Ambiente Virtual de Aprendizaje (AVA). Así, el propósito de este informe es presentar y discutir las estratégias adoptadas en las clases y actividades evaluativas. Se observa que, dado el carácter excepcional del año 2020, de pandemía y educación remota, se logró mantener relaciones importantes, como maestro-alumno y escuela-alumno. Además, es posible afirmar que la variación em los métodos de enseñanza proporcionó compromiso, interés e involucramiento de los estudiantes, lo cual se evidenció por la participación en clases sincrónicas y por los comentarios posteriores a la realización de las actividades. De esta forma, lo que sería una posibilidad de emergencia para el contexto docente actual se ha convertido en una herramienta importante a la hora de retomar las actividades presenciales.

Palabras clave: Geografía; Enseñanza Remota; Enseñanza-Aprendizaje.

\section{Introdução}

A educação transcendeu seus sustentáculos físicos com o advento das tecnologias principalmente após a segunda metade do século XX e tornou-se possível de forma remota. Esta não é uma demanda atrelada apenas ao contexto dos meios informacionais, mas é irrefutável que após a consolidação dos sistemas computacionais e, sobretudo com a ampliação do acesso à rede mundial de internet, a Educação à Distância $(\mathrm{EaD})$ tornou-se notável como força motriz educacional e ganhou amplas e irrestritas possibilidades. Trata-se de um formato sistematicamente organizado de autoestudo quando os alunos se instruem a partir de conteúdos digitais síncronos ou assíncronos que lhes são apresentados, na presença virtual do professor, seus tutores e equipe de ensino, conforme pressupõem Veiga et al. (1998).

A educação não se resume a uma transferência de saber. É um processo pautado no diálogo, na comunicação, na medida em que haja um encontro de sujeitos interlocutores que buscam a significação dos significados. O acesso e a dispersão de tecnologias devem ser tratados como uma ferramenta comunicacional. Numa relação de ensino-aprendizagem há reciprocidade: dialógica, crítica e ações emocionais. Essa relação é um dos componentes fundamentais da educação.

A pandemia da COVID-19 trouxe uma série de impactos que, na Educação, se fizeram marcantes na medida em que as aulas foram suspensas, no Brasil e na maior parte do mundo em 2020, acarretando a necessidade de se adotar um ensino remoto em caráter emergencial. Salienta-se que na contemporaneidade existem recursos de softwares de alta performance e especificidades, mas, tratando-se do emprego destes na educação, e esta como um campo 
vasto de formação do ser humano, a maior dificuldade talvez seja a escolha metodológica para empregá-los de forma que se alcance aprendizagem e inserção do indivíduo em seu contexto social.

A partir de todo o exposto, pretende-se, com este trabalho, apresentar e discutir algumas possibilidades para o ensino de Geografia, representantes de diferentes estratégias de aprendizagem, que foram utilizadas ao longo do ano de $2020 \mathrm{com}$ turmas de $1^{\mathrm{o}}$ ano do Instituto Federal de Educação, Ciência e Tecnologia de Minas Gerais (IFMG), no campus Betim. Salienta-se que a Organização Mundial da Saúde (OMS) decretou a COVID-19 como pandemia em 11 de março de 2020. Em 17 de março, por meio da Portaria $\mathrm{N}^{\circ} 343$, o Ministério de Estado da Educação (MEC) autorizou a substituição das aulas presenciais por aulas que utilizassem "meios e tecnologias de informação e comunicação" (Brasil, 2020, Art. $1^{\circ}$ ). No dia seguinte, o IFMG suspendeu as aulas e autorizou o ensino remoto, sendo que no campus Betim a substituição pela nova modalidade de ensino correu de maneira imediata.

\section{Apoio Teórico}

De acordo com Freire (1996), o educar a partir da problematização e da situação do sujeito em seu meio envolve trazer à tona os problemas inerentes a um objeto da realidade e sobre ele promover o diálogo que transformará as concepções dos alunos e dos professores. Nesse sentido, há de se trazer significantes e significados ao público-alvo quando se trabalha com metodologias tecnológicas no processo de ensino-aprendizagem. Partindo do princípio de que uma comunicação é caracterizada pelo diálogo, caberia buscar interferências que permitam aos interlocutores "falar e ouvir" sempre, em canais sem prejuízos.

A comunicação envolve, assim, inúmeros campos do conhecimento e sua problemática na educação é abordada pela pedagogia e sociologia da educação quando tratam da influência das mídias e formas de expressividade e/ou alcance na sociedade, além de suas mudanças proporcionadas no âmbito escolar. Silva (2019) aponta que nessa abordagem não se compreende a comunicação como algo mecânico e simplificado com a finalidade de dialogar, pois o caminho da formação cidadã e ampla que a educação permite aos seres humanos vai além do falar e ouvir. O apreender deve conectar os atores do processo ensino-aprendizagem, promovendo uma interação crítica de ambas as partes e com metodologias diferenciadas e, principalmente, planificadas. A oralidade nesse caso faz parte do processo, mas é somente uma de muitas outras estratégias, conforme também apresentado em Silva (2019). 
Research, Society and Development, v. 9, n. 12, e14491210945, 2020

(CC BY 4.0) | ISSN 2525-3409 | DOI: http://dx.doi.org/10.33448/rsd-v9i12.10945

O espaço cognitivo entre professor e aluno num ambiente educacional, denominado distância transacional, conforme Moore (2002), possui ideias que tornam factíveis a transformação de processos de comunicação de conteúdos formativos em educação à distância: o diálogo, que se refere à interação entre alunos e professores independentemente de como ele é possibilitado; a estrutura dos programas de ensino, que confere o planejamento adotado; e a autonomia do aluno, que naturalmente será regida pela distância até o professor e guiada também pelo compromisso e interesse do educando. Dessa maneira, crê-se que é possível promover uma educação à distância, considerando os princípios da comunicação na educação, sobretudo no campo da interação e seguindo métodos de orientação e estruturação.

Neto \& Dias (2011) destacam que a ciência geográfica se constitui como ciência social, que deve considerar o aluno e a sociedade em que vive. Dessa forma, não pode ser descontextualizada da realidade de vivência do aluno. Para isso, é preciso ir além de descrições de lugares e paisagens. O ensino de Geografia deve caminhar para que o aluno possa se perceber como parte e agente do espaço que estuda. Callai (2001) aponta que

O aluno deve estar dentro daquilo que está estudando e não fora, deslocado e ausente daquele espaço, como é a geografia que ainda é muito ensinada na escola: uma geografia que trata o homem como um fato a mais na paisagem, e não como um ser social e histórico (Callai, 2001, p.58).

Cavalcanti (2012), ao tratar a geografia escolar, salienta que ela apresenta conteúdos relacionados aos "aspectos naturais e sociais (...) de diferentes lugares do mundo, 'agrupados' de diferentes formas, por regiões, por continentes, para que sejam aprendidos pelos alunos" (Cavalcanti, 2012, p.134). Porém, Ascenção \& Valadão (2017) apontam que é comum visualizar a prática docente como simples comunicação de informações sobre algum assunto, onde conceitos são apenas informados, sem a devida contextualização. Assim, afirma ser necessária uma Geografia Escolar baseada em "práticas pedagógicas que utilizem conceitos não como objetivo final da aprendizagem, mas "como meio que favoreça o reconhecimento das interações entre diversos e diferentes componentes espaciais" (Ascenção \& Valadão, 2017, p.6).

Outro aspecto a se considerar é o papel da educação na formação do indivíduo e nesse contexto, Vlach (2007) destaca os raciocínios geográficos como fundamentais, tendo em vista que tornam possíveis o conhecimento do próprio território em que a sociedade vive. Logo, também seria função da Geografia Escolar o estímulo a esse tipo de raciocínio como tentativa 
(CC BY 4.0) | ISSN 2525-3409 | DOI: http://dx.doi.org/10.33448/rsd-v9i12.10945

de contribuir para a "compreensão de problemas do mundo atual, muitos dos quais estão ligados à convivência social no seu sentido mais amplo" (Vlach, 2007, p.4).

A aula, para Cavalcanti (2017), é centro do trabalho docente, devendo se dar de maneira a provocar e estimular o aluno, evidenciando a relação deste com a realidade. Para a autora, essa relação é mediada por determinados instrumentos materiais e simbólicos no ambiente escolar. Especificamente para a Geografia, há a intenção de formação de conceitos geográficos que possam instrumentalizar os sujeitos no relacionamento para com a realidade. Assim, a Figura 1 apresenta um esquema de metodologia para orientar a mediação didática geográfica.

Figura 1. Elementos de Metodologia de Ensino e a Geografia Escolar.

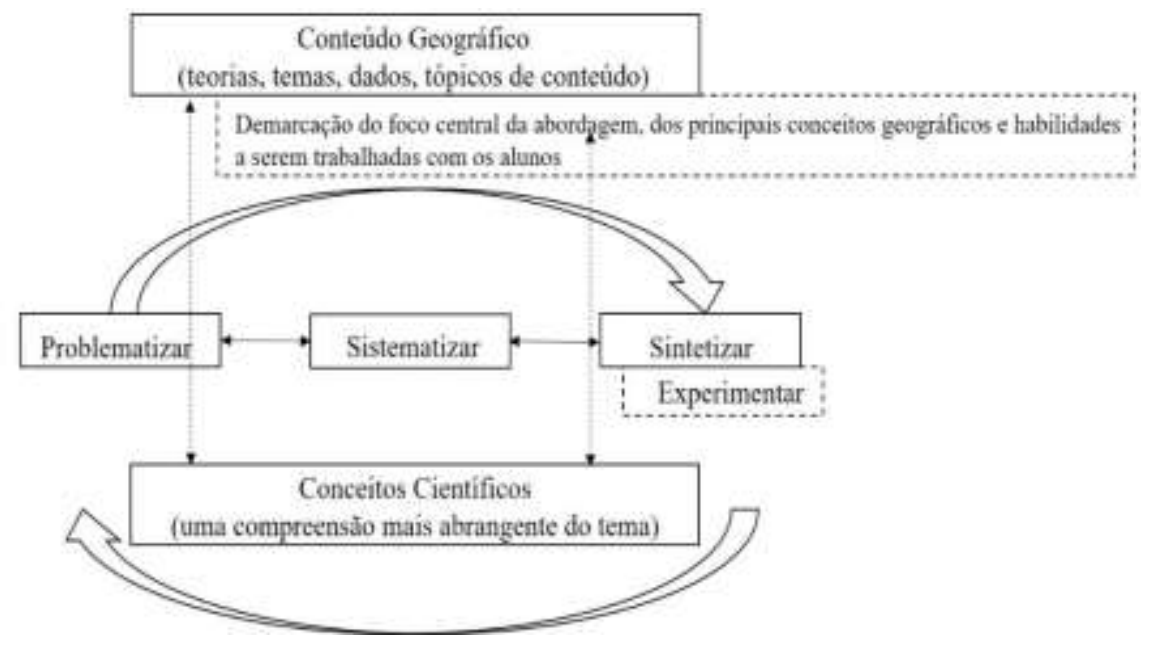

Fonte: Cavalcanti (2017).

Salienta-se que o modelo proposto por Cavalcanti (2017) se baseia na concepção de Vygotsky (2000) de que "os conceitos são formados na mente dos sujeitos a partir de um problema cuja resolução só pode ser encaminhada com a ajuda de um novo conceito" (Cavalcanti, 2017, p.114). Tomando a compreensão da espacialidade dos fenômenos como objeto de estudo da Geografia, pretende-se, por meio da educação geográfica, alcançar uma forma de pensar que seja complexa, ampla, interligada e capaz de fomentar um pensamento crítico que embasaria a própria formação dos sujeitos (Callai, 2011). Para tanto, torna-se necessário o trabalho baseado na ideia de aprendizagens significativas, onde a Geografia seria uma disciplina que vai além da apresentação de sequências de ilustrações.

Dessa maneira, quando se considera o conteúdo programático de Geografia para o $1^{\circ}$ Ano do Ensino Médio no Instituto Federal de Educação, Ciência e Tecnologia de Minas Gerais (IFMG), campus Betim, há o desafio de se trabalhar com conceitos relacionados à 
Introdução à Ciência Geográfica, Cartografia e Geografia Física. Somado à extensão dos conteúdos há o contexto da pandemia da COVID-19, bem como a consequente implementação do Ensino Remoto Emergencial. Logo, houve a necessidade de capacitação de docentes e discentes e suporte técnico e estrutural para utilização de um, já existente, Ambiente Virtual de Aprendizagem.

Felder \& Silverman (1988) apontam que os alunos aprendem de maneiras diferentes e variadas, alguns vendo, outros ouvindo, refletindo, agindo, memorizando. Da mesma maneira que os métodos de ensino também variam. Dessa forma, o nível de aprendizagem de um aluno pode estar diretamente relacionado à compatibilidade existente entre o seu estilo de aprendizagem e o estilo de ensino de quem leciona.

Pereira \& Vieira Júnior (2013) destacam que os "estilos de aprendizagem tratam da forma como um indivíduo recebe, processa e organiza seu conhecimento, tendo como base sua tipologia e personalidade" (Pereira \& Vieira Júnior, 2013, p.174). Logo, conforme Lopes (2002), o conhecimento em relação ao estilo de aprendizagem dos alunos (assim como eles próprios se conhecerem nesse sentido) pode garantir melhor engajamento nos estudos. Daí a importância, também, de que o professor faça uso de diferentes abordagens e técnicas, de maneira a garantir que o maior número de alunos possa ser atingido.

Uma possibilidade a ser trabalhada no ensino seria aquela a partir dos Modelos Mentais, que, segundo Moreira (1996), propiciam representações facilitadoras da cognição humana. Esses modelos podem representar as soluções mentais que as pessoas adotam para compreender e interagir com sistemas do mundo físico. Assim, um modelo deve permitir a alguém responder perguntas que descrevem e explicam o sistema: Como é o sistema (descreva o sistema)?; De que o sistema é formado (descreva a estrutura do sistema)?; Como ele funciona (explique o funcionamento)?; O que ele está fazendo (preveja ou explique o estado do sistema)?; Para que ele serve (descreva o propósito do sistema)?

Destaca-se que as pessoas não captam o mundo exterior diretamente, elas constroem representações mentais dele. Os modelos mentais são, portanto, uma forma de representação analógica do conhecimento: existe uma correspondência direta entre entidades e relações presentes na estrutura dessa representação e as entidades e relações que se busca representar (Moreira, 1996).

No ensino, o professor ensina modelos conceituais e espera que o aprendiz construa modelos mentais consistentes com esses modelos conceituais que, por sua vez, devem ser consistentes com os sistemas físicos modelados. Os modelos conceituais são, portanto, instrumentais, meios e não fins. O objetivo do ensino é, através de modelos conceituais, levar 
o aprendiz a formar modelos mentais adequados. Para isso é preciso desenvolver modelos conceituais e materiais, estratégias instrucionais que ajudem os aprendizes a construir modelos mentais adequados. A aprendizagem será significativa quando uma nova informação adquire significado para o aluno através de uma espécie de conexão com aspectos cognitivos e conceitos pré-existentes (Moreira, 1998).

Também há que se destacar a importância da avaliação no ensino como instrumento de verificação da aprendizagem. Pironel (2017) aponta que a avaliação é capaz de fornecer subsídios ao professor para a evolução de sua própria prática docente, levando a um questionamento quanto à finalidade da avaliação, o tempo de realização, o engajamento dos alunos pela atividade, dentre outras questões.

Em relação à avaliação em sala de aula, é preciso pensar numa metodologia denominada ensino-aprendizagem-avaliação: quando há a resolução de problemas (Pironel, 2017). Estes três processos são realizados de forma individual e distinta. Por outro lado, podem acontecer em pares. Por exemplo: ao mesmo tempo em que se ensina, pode-se garantir a aprendizagem ou ao passo que há aprendizagem, testa-se o conteúdo visto por meio da avaliação.

Considera-se que, além das provas escritas, individuais ou coletivas, ou diários interativos, o professor deve buscar a conexão entre os conteúdos apresentados, o feedback pontual do educando e o planejamento de atitudes para melhorar o desempenho do aluno. Toda avaliação apresenta evidências a respeito do trabalho que está sedo desenvolvido, produzindo, também, uma reflexão sobre a atividade avaliativa. E por que não convidar os discentes para participar desta meta-avaliação? Há de se considerar a avaliação como uma oportunidade de diálogo. Para isso ela deve ser um processo dinâmico e constante em sala de aula, sempre priorizando estratégias equilibradas.

\section{Metodologia}

Para o desenvolvimento deste trabalho foi necessário, primeiramente, um levantamento bibliográfico acerca das temáticas relacionas à educação geográfica, métodos de ensino, aprendizagem e avaliação. A partir desse levantamento, buscou-se uma reflexão acerca da prática docente, bem como um embasamento para possibilidades a serem utilizadas durante o Ensino Remoto Emergencial.

Dessa forma, este trabalho consiste em um relato de experiência que apresenta os resultados obtidos a partir de uma análise qualitativa em que foram observados os principais 
aspectos que se destacaram no ensino de Geografia, via Ambiente Virtual de Aprendizagem, ao longo do ano de 2020. Salienta-se que, conforme Pereira et al. (2018, p.67), "os métodos qualitativos são aqueles nos quais é importante a interpretação por parte do pesquisador com suas opiniões sobre o fenômeno em estudo". Assim, após apresentar alguns dos métodos utilizados, é feita uma análise crítica sobre o método em si e, também, sobre a receptividade e o envolvimento dos alunos.

\section{Ensino Remoto Emergencial e o Ambiente Virtual de Aprendizagem (AVA)}

Com a adoção do ensino remoto emergencial, a direção do campus Betim iniciou uma série de reuniões de planejamento, de maneira que uma das decisões tomadas foi a de alternância entre aulas das disciplinas da formação geral e as de conteúdo técnico. Assim, ficou definido que em uma semana os alunos teriam apenas as propedêuticas e na outra semana seriam as técnicas. Destaca-se a sugestão para que as atividades avaliativas fossem aplicadas em todos as aulas, de forma que o prazo de entrega permanecesse por duas semanas. Ou seja, na semana em que não houvesse aula (síncrona ou assíncrona) com distribuição de conteúdo de Geografia, por exemplo, os alunos teriam um plantão de atendimento e atividades a serem cumpridas.

Uma consideração a ser feita é que a instituição já possuía um Ambiente Virtual de Aprendizagem, com cadastro regular dos alunos no qual, frequentemente, parte do corpo docente disponibilizava conteúdos complementares e aplicava avaliações especiais. Dessa forma, utilizou-se essa plataforma como oficial para todas as disciplinas, o que contribuiu para a (rápida) organização dos estudos dos alunos e das aulas dos professores.

Como forma de exemplificar como a disciplina de Geografia se estruturou nesse momento, a seguir, será apresentada a programação de quatro aulas de diferentes temáticas voltadas para o $1^{\circ}$ ano. Em cada uma das aulas, buscou-se trabalhar com práticas e métodos de ensino diversos:

\footnotetext{
. "Geografia e Pandemias"

. "Cartografia e Geotecnologias"

. "Introdução à Geologia do Planeta"

. "Geomorfologia e Pedologia".
} 
Research, Society and Development, v. 9, n. 12, e14491210945, 2020

(CC BY 4.0) | ISSN 2525-3409 | DOI: http://dx.doi.org/10.33448/rsd-v9i12.10945

Dessa forma, na primeira aula houve a disponibilização de um podcast de autoria própria, introduzindo a temática da relação entre a ciência geográfica e as pandemias (Quadro 1). A ideia, nesse momento inicial, era despertar a atenção dos alunos para a importância do assunto, além de introduzi-los ao ensino remoto, demonstrando a existência de diferentes tecnologias que podem ser utilizados no ensino como ótimas ferramentas para aprendizagem. Com isso, além do podcast, foram disponibilizados materiais textuais, visuais e proposta uma atividade avaliativa reflexiva sobre o contexto da pandemia, sua influência e seu impacto na vida dos alunos e sua relação com a Geografia. Por fim, foi criado um espaço para fórum específico para que os alunos esclarecessem suas dúvidas.

Quadro 1. Conteúdo organizado e disponibilizado para a primeira aula.

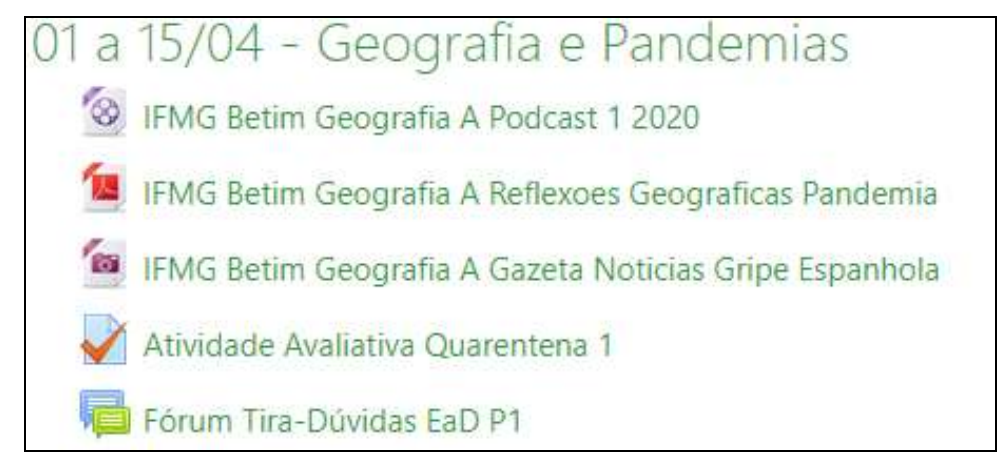

Fonte: Acervo pessoal.

Menezes (2009), avaliando a utilização de podcasts para a aprendizagem da língua inglesa, destacou as potencialidades da ferramenta, na medida em que se comporta como um prolongamento do espaço físico da sala de aula. A autora destaca que o podcast é composto por um conjunto de áudios que pode ser compartilhado online, sendo alojado em várias ferramentas da web. Após a publicação, os utilizadores podem fazer download para seus dispositivos móveis. Essa é, portanto, uma das vantagens dos podcasts, tendo em vista que haverá respeito aos diferentes ritmos de aprendizagem (os alunos podem acessar e ouvir o arquivo quantas vezes for necessário, até compreenderem o conteúdo abordado).

Outras vantagens do uso dos podcasts podem ser relacionadas ao interesse despertado nos alunos por se tratar de uma ferramenta nova utilizada na aprendizagem, além do fato de que sua produção é simples, não envolvendo a necessidade de conhecimentos técnicos avançados. Menezes (2009) salienta que basta "um computador com ligação à Internet, um microfone e o respectivo software para a digitalização do som (Menezes, 2009, p. 46)".

Para a confecção do podcast relacionado na aula aqui tratada, utilizou-se apenas o próprio gravador de voz do dispositivo móvel. Primeiramente, foi elaborado um roteiro para a 
(CC BY 4.0) | ISSN 2525-3409 | DOI: http://dx.doi.org/10.33448/rsd-v9i12.10945

gravação da sequência de voz. Este roteiro foi embasado no conteúdo do programa de Geografia, do livro didático e outras referências bibliográficas. Para compor o áudio, foi escolhida uma música de abertura e encerramento. Em seguida, a gravação foi executada. Após a finalização, o arquivo foi disponibilizado aos alunos.

No Quadro 2 é possível observar os materiais utilizados na aula sobre Geologia, em que foram disponibilizados áudios, videoaulas, indicações de textos didáticos e complementares, além de um documentário. Houve ainda fórum para dúvidas e exercícios de fixação. Destaca-se que a sugestão do documentário teve como objetivo que os alunos pudessem compreender o conteúdo em questão sob outro ponto de vista, de maneira aplicada e mais próxima da realidade. Dessa forma, seria possível o aluno se perceber inserido e pertencente ao contexto do conteúdo estudado, o que é importante para a ciência geográfica, conforme apontado por Neto \& Dias (2011).

Quadro 2. Conteúdo apresentado aos alunos na aula sobre Geologia do Planeta.

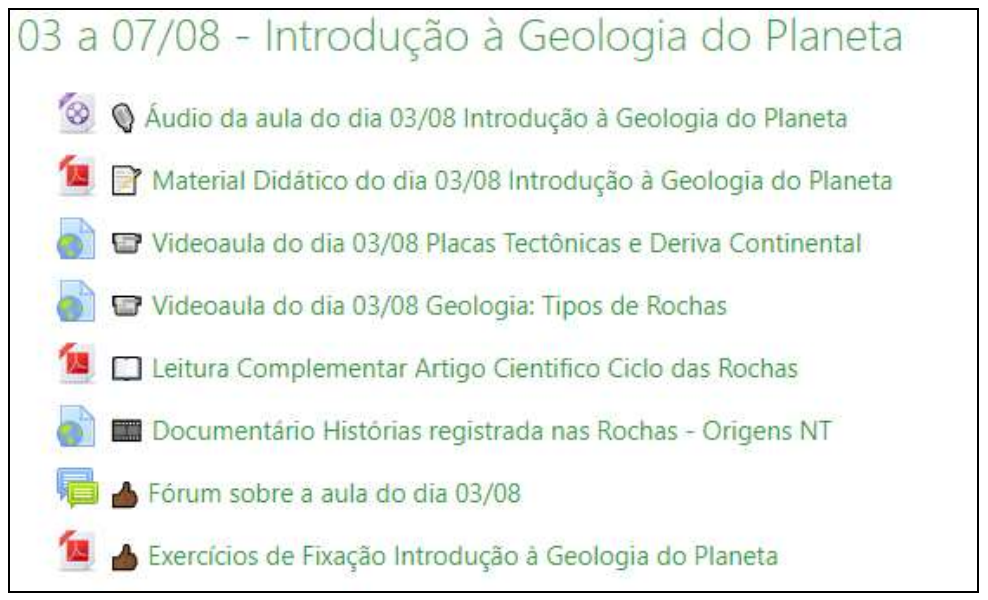

Fonte: Acervo pessoal.

Os conteúdos de Geomorfologia e Pedologia foram trabalhados também por meio de materiais variados, a começar por uma aula síncrona, via Google Meet (Quadro 3). Os alunos tiveram acesso, ainda, a materiais didáticos textuais e indicações de videoaulas disponibilizadas em canais na internet, como o Youtube. Houve exercícios de fixação, fórum para dúvidas e duas propostas de atividades avaliativas, sendo uma de múltipla escolha e outra em que os alunos deveriam elaborar um mapa conceitual que abordasse, de forma esquemática, os principais conceitos relacionados às estruturas e formas de relevo. 
Research, Society and Development, v. 9, n. 12, e14491210945, 2020

(CC BY 4.0) | ISSN 2525-3409 | DOI: http://dx.doi.org/10.33448/rsd-v9i12.10945

Quadro 3. Conteúdo postado para a aula sobre Geomorfologia e Pedologia

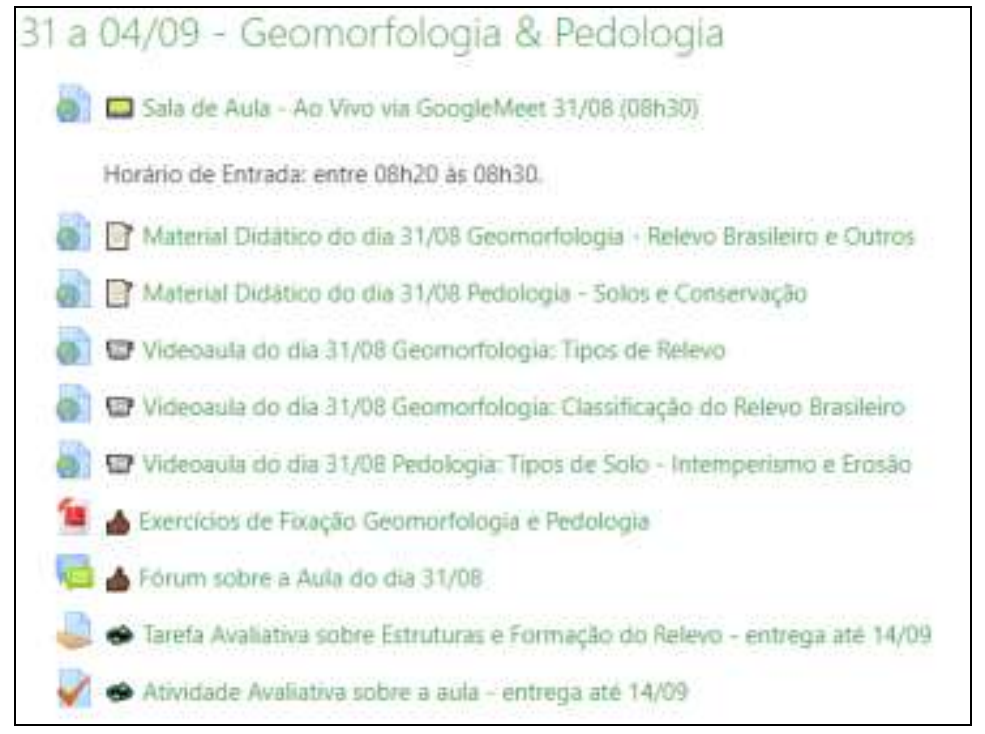

Fonte: Acervo pessoal.

Salienta-se que a atividade baseada na elaboração do mapa conceitual buscou verificar a compreensão e o entendimento dos conteúdos a partir da externalização dos alunos, conforme também apontado por Moreira (1998). Ou seja, o mapa conceitual seria uma forma para que os estudantes demonstrassem o modelo mental desenvolvido para a interpretação dos conceitos e das informações sobre estruturas e formas de relevo.

\section{Desenvolvimento e Resultados das Estratégias Adotadas}

A aproximação e inserção do público jovem (sobretudo adolescente) - educandos em questão nesse relato de experiência - com os meios informacionais na contemporaneidade é um ponto de vista facilitador e considerável para a trajetória no ensino remoto emergencial. No panorama contemporâneo, os indivíduos que possuem acesso mantêm contato, com intensidade, via tecnologias digitais em seu cotidiano, em especial, o grupo etário entre os 11 aos 17 anos. A rede de informações é um recurso potente e transformador das comunicações interpessoais, "a começar pelas famílias, desde a inserção do rádio e da TV e, posteriormente, com a invenção do computador e da internet, principalmente a partir do surgimento das redes sociais virtuais" (Silva \& Silva, 2017, p.94).

$\mathrm{O}$ incremento de uso de tecnologias no processo decorreu em ações educativas semelhantes na grande maioria dos países, influenciando também a formação das gerações mais jovens, consumidoras das tecnologias de interações virtuais. Essa aproximação e sincronismo das mudanças educativas em regiões distintas do planeta deve-se, também, às 
oportunidades geradas "pela mais extraordinária revolução tecnológica da humanidade", como aponta Castells (2005), referindo-se às Tecnologias de Comunicação e Informação, fundamentadas majoritariamente nas redes digitais de computadores. O reconhecimento global desta revolução e o uso das TDICs na educação do Brasil têm sido discutidos e incorporados ao longo das últimas décadas para propiciar um aumento na qualidade metodológica dos projetos educacionais - o que representa um grande desafio como reforçam Allan \& Piconez (2010) - ou simplesmente a busca por um atendimento mercadológico, a partir da expansão recente da EaD no país.

Sobre a reflexão das aplicações de ensino de geografia, aprendizagem e avaliações trazidas nesse ano de 2020, portanto, é preciso salientar que houve certa facilidade para desenvolver ações que envolveram o manuseio de aplicativos de smartphones, softwares de edição de imagens e vídeos, jogos (gamificação), acesso a vídeos em diferentes plataformas incluindo redes sociais, pois, foi um incentivo à operacionalização de objetos e estruturas as quais fazem parte do habitual de boa parte dos educandos. Reconhece-se também a questão locacional da instituição de ensino e da maior parte do corpo discente observado (região metropolitana), que, apesar de suas mazelas e desigualdades socioeconômicas, pode propiciar uma vivência e experimentação de velocidade cotidiana, reforçando o caráter dinâmico de fluxo de informações e possibilidades de acesso aos meios comunicacionais.

É importante ressaltar que na referida escola deste estudo houve "adesão geral" ao ensino remoto emergencial, o que possibilitou trabalhar com o cadastro-virtual-total dos alunos. Houve inicialmente receio em progredir o ano letivo via ensino remoto. Sabe-se que numa realidade socialmente impactante como uma pandemia, os desafios seriam imensos e o rumo incerto - isento de planejamento - poderia decorrer na ampliação das desigualdades internas e externas.

Com as indicações de distanciamento social recomendadas pela Organização Mundial da Saúde, a inclusão digital teve que ser disseminada tanto para alunos quanto para professores. Aos docentes caberia uma adaptação abrupta e urgente a uma nova modalidade; aos educandos, principalmente inseridos em camadas mais vulneráveis, haveria um enfrentamento a uma série de dificuldades estruturais, como a ausência de dispositivos de informática ou a falta de conexão com a internet; e a todos os envolvidos pode-se enaltecer as questões de sobrevivência, uma vez que as famílias experimenta(ra)m uma conjuntura socioeconômica e de saúde extremamente conflitante, como aponta Neira (2020).

Entretanto, há de se reconhecer que nesse estudo de caso houve apoio institucional via campus, ao propiciar empréstimo de notebooks, tablets; o incentivo à aquisição de pacote de 
dados de internet via assistência social; a elaboração de videoaulas instrutivas para os alunos se aprimorarem no manuseio do ambiente virtual de aprendizagem; além da participação ativa do setor de pedagogia, com o atendimento a alunos e responsáveis (pais) via telefone, e-mail e videoconferência. Ou seja, houve aparato financeiro, técnico e humano para ampliar a adesão ao Ensino Remoto Emergencial. Dessa maneira há aqui um caráter de excepcionalidade também nas condições de trabalho. Nesse ínterim é, portanto, notável o contraste entre as possibilidades do IFMG frente a outras escolas públicas, sejam elas municipais ou estaduais.

As avaliações podem ser consideradas elementos importantes para refletir sobre a aprendizagem dos alunos. Pode ser a partir do desempenho destas que cada estudante reconheça seu percurso de apropriação pessoal de conhecimentos e experiências. Em contrapartida, supõe-se que durante a realização de uma avaliação seja construído um momento de oportunidade de aprendizagem, não uma simples medição de erros e acertos (ou teste). Nesse sentido, a avaliação deveria ser aplicada quando o educando se sinta apto a explanar os saberes por si assimilados.

Logo, a desobrigação do mito da "prova" foi evidenciada como um caminho menos conflituoso, sobretudo no ensino remoto emergencial. Por isso, optou-se na disciplina Geografia por abolir as avaliações no formato prova, com data e hora marcada. Os métodos avaliativos empregados foram: a participação nas aulas síncronas e acesso às aulas assíncronas; a resolução de questões objetivas; o envolvimento com os conteúdos audiovisuais, a partir da participação comentada sobre o tema (método dissertativo em fórum ou produção de texto) e a apresentação diferenciada de conteúdos absorvidos por meio de mapas mentais e/ou áudios. Todas estas modalidades respeitando o calendário (prazo) quinzenal das aulas.

Privilegiou-se, portanto, a horizontalidade das relações, a autonomia dos educandos, o trabalho em equipe dos professores e a ação educativa destes, mais baseada no apoio do que na comunicação magistral (conteudista) e, mesmo, a possibilidade de os alunos trabalharem individual ou coletivamente, exprimindo um conjunto de atividades desenvolvidas em aprendizagem flexível (Silva \& Ribeiro, 2018). A escolha por avaliações "não-tradicionais" teve o aval das unidades gestoras da escola e foi socializada entre os pares nas reuniões trimestrais dos conselhos de classe.

Ações avaliativas diferenciadas, coletivas (ou não) e sucintas, aplicadas ao longo do processo de ensino-aprendizagem, permitem "perceber o grau de aproveitamento dos alunos e suas principais dificuldades, possibilitando o planejamento adequado para atingir os objetivos desejados" (Souza \& Menezes, 2014, p.167). Essa metodologia pode ser classificada como 
avaliação formativa. Dada também a atribulação de outras tantas disciplinas em que os estudantes se encontravam, destaca-se que esse tipo de proposta pode estar voltada para a formação de pessoas capazes de realizar tarefas, resolver problemas e construir novos saberes. Dessa forma houve feedback positivo na caminhada dos educandos, principalmente num momento de pandemia, buscando trazer ao cronograma escolar uma tentativa de conforto psicológico. Soma-se a isso a intencionalidade "celular", pontual de retorno dos conteúdos nas ações avaliativas, indo ao encontro do modus operandi da modalidade EaD.

\section{Considerações}

Apesar do receio inicial da ampliação das desigualdades, quando na decisão pelo Ensino Remoto Emergencial por meio do Ambiente Virtual de Aprendizagem, o fomento institucional com os educandos, reunião de pais e todas as outras ações (de forma virtual) propositivas e coletivas contribuíram para o cumprimento do ano letivo. A experiência presencial é diferenciada principalmente no que tange ao feedback do nível de compreensão dos conteúdos (já que é quase que imediato), mas, diante da complexidade do ano, é possível afirmar que o trabalho docente e o envolvimento discente foram os melhores possíveis.

O contato com o conhecimento pedagógico e as principais teorias de aprendizagem foram fundamentais para planejar, elaborar e transitar entre diferentes produtos para a apresentação dos conteúdos nas aulas síncronas ou assíncronas e, também, nas propostas de atividades avaliativas. Nesse sentido, tornou-se explícita a importância de se estudar e aplicar conhecimentos sobre teorias e métodos na educação.

Além disso, o esforço para a utilização de práticas diversas foi reconhecido pelos educandos, na medida em que houve retorno positivo. Acredita-se que o fato de as atividades serem distribuídas quinzenalmente, acrescido do uso variado de metodologias tenham sido determinantes tanto para a participação dos alunos nas aulas quanto nas entregas das atividades. Destacou-se o envolvimento dos discentes especialmente no fórum de comentários após a exibição de documentário e a satisfação dos alunos ao criar seu próprio podcast, ou seja, sendo sujeitos no processo de construção do conhecimento.

Constata-se, assim, a importância da variação e do incremento de novos métodos de ensino, que possam contribuir para a efetividade das relações de ensino-aprendizagem em contextos específicos. Espera-se que outros trabalhos também possam apresentar relatos como os aqui apresentados, de possibilidades para o ensino em tempos de pandemia e excepcionais. Sugere-se, ainda, que estudos futuros busquem quantificar o nível de envolvimento e 
Research, Society and Development, v. 9, n. 12, e14491210945, 2020

(CC BY 4.0) | ISSN 2525-3409 | DOI: http://dx.doi.org/10.33448/rsd-v9i12.10945

desempenho dos alunos em cada atividade proposta, como forma de verificar quais métodos se destacam no Ensino Remoto Emergencial em termos de participação discente.

\section{Referências}

Allan, L. M.; \& Piconez, S. C. B. (2010). Aprender em parceria: estudo de metodologia para inserção das TDIC na formação continuada de professores da educação básica. In: Tic y Educación. Congreso Iberoamericano de Educación - Metas 2021. Buenos Aires, Argentina.

Ascenção, V. O. R.; \& Valadão, R. C. (2017). Complexidade conceitual na construção do conhecimento do conteúdo por professores de Geografia. In: Revista Brasileira de Educação em Geografia, Campinas, v. 7, n. 14, p. 05-23.

Brasil. Portaria No343, de 17 de março de 2020. (2020). Recuperado de: https://www.in.gov.br/en/web/dou/-/portaria-n-343-de-17-de-marco-de-2020-248564376.

Callai, H. C. (2001). O ensino de Geografia: recortes espaciais para análise. In: Castrogiovanni, Antônio C. et al (orgs). Geografia em sala de aula: práticas e reflexões. $3^{\text {a }}$ ed. Porto Alegre: UFRGS/AGB, p. 57-63.

Callai, H. C. (2011). A Geografia Escolar - e os conteúdos da Geografia. In: Revista Anekuneme, n.1, p.128-139.

Castells, M. A. (2005). Sociedade em Rede: do conhecimento à política. In: Castells, M.; Cardoso, G. [orgs.]. A Sociedade em Rede: do conhecimento à ação política. Lisboa, INMC, p. 17-30.

Cavalcanti, L. S. (2012). Concepções teórico-metodológicas e docência da Geografia no mundo contemporâneo. In: O ensino de geografia na escola. Campinas, São Paulo: Papirus, p208.

Cavalcanti, L. S. (2017). O trabalho do professor de geografia e tensões entre demandas da formação e do cotidiano escolar. In: Ascenção, V. O. R. [et al.] Conhecimentos da Geografia: percursos de formação docente e práticas na educação básica. Belo Horizonte; IGC, p. 100123. 
Felder, R., \& Selverman, L. (1998). Learning and teaching styles in Engineering Education. In: Journal of Engineering Education, 78(7), 674-681.

Freire, P. (1996). Pedagogia da Autonomia: saberes necessários à prática educativa. São Paulo: Paz e Terra.

Lopes, W. M. G. (2002). ILS inventário de estilos de aprendizagem de Felder-Soloman: investigação de sua validade em estudantes universitários de Belo Horizonte. 2002. 107 f. Dissertação (Mestrado em Engenharia de Produção) - Universidade Federal de Santa Catarina, Florianópolis.

Menezes, C. M. C. A. V. Q. (2009). Utilização de dispositivos móveis na escola do séc. XXI: o impacto do podcast no processo ensino-aprendizagem da língua inglesa no $7^{\circ}$ ano do $3^{\circ}$ ciclo do Ensino Básico. Dissertação de Mestrado. Universidade Portucalense Infante D. Henrique. 119p.

Moore, M. G. (2002). Teoria da Distância Transacional. Revista Brasileira de Aprendizagem Aberta e a Distância, v. 1. São Paulo. Recuperado de: http://migre.me/wKbpV.

Moreira, M. A. (1997). Modelos Mentais. In: Investigações em Ensino de Ciências, Porto Alegre, v. 1, n. 3, pp. 193-232, 1996. Trabalho apresentado no Encontro sobre Teoria e Pesquisa em Ensino de Ciências - Linguagem, Cultura e Cognição, Faculdade de Educação da UFMG, Belo Horizonte.

Moreira, M. A. (1998). Mapas conceituais e aprendizagem significativa. Cadernos de Aplicação, Porto Alegre, v. 11, n. 2, p. 143-156.

Neira, M. G. (2020). Desigualdade social afeta adesão ao ensino remoto. In: Jornal da USP no Ar. Universidade de São Paulo.

Neto, F. O. L., \& Dias, R. H. L. (2011). Mapas mentais e a construção de um ensino de geografia significativo: algumas reflexões. In: Revista Eletrônica Geoaraguaia. Barra do Garças-MT. v1, n.1, p.1-12. 
Pereira, E. J. \& Vieira Júnior, N. (2013). Os Estilos de Aprendizagem no Ensino Médio a partir do Novo ILS e a Sua Influência na Disciplina de Matemática. In: Alexandria - Revista de Educação em Ciência e Tecnologia, v.6, n.3, p.173-190.

Pereira, A. S., Shitsuka, D. M., Parreira, F. J., \& Shitsuka, R. (2018). Metodologia da pesquisa científica. 1. ed. - Santa Maria, RS: UFSM, NTE. Recuperado de: https://repositorio.ufsm.br/bitstream/handle/1/15824/Lic_Computacao_MetodologiaPesquisa-Cientifica.pdf? sequence $=1$.

Pironel, M. (2017). O papel da avaliação na metodologia de ensino aprendizagem avaliação de matemática através da resolução de problemas. In: Onuchic, L R; Leal Junior, L C; Pironel, M. Perspectivas para Resolução de Problemas. São Paulo, Livraria da Física.

Silva, T. O.; \& Silva, L. T. G. (2017). Os impactos sociais, cognitivos e afetivos sobre a geração de adolescentes conectados às tecnologias digitais. In: Revista Psicopedagogia vol. 34(103): 87-97. São Paulo.

Silva, A. R. L. (2019). Experiências significativas para a educação à distância [recurso eletrônico]. Ponta Grossa (PR): Atena Editora, v.1.

Silva, C. M.; \& Ribeiro, C. (2018). A apropriação do espaço escolar pelo projeto pedagógico: o caso da Escola da Ponte (Portugal). In: Revista Educação e Pesquisa vol.44. São Paulo.

Souza, T. E. S.; \& Menezes, A. H. N. (2014). Avaliação em Educação a Distância: concepções e possibilidades. REVASF, Petrolina, PE, vol. 4, n. 6, p. 158-170.

Veiga, R. T.; Moura, A. I.; Gonçalves, C. A.; \& Barbosa, F. V. (1998). O Ensino à Distância pela Internet: Conceito e Proposta de Avaliação. 22 Encontro da ANPAD. ENANPAD 1998: Associação Nacional de programas de Pós-Graduação em Administração. Foz do Iguaçu.

Vlach, V. (2007). Papel do ensino de geografia na compreensão de problemas do mundo atual. In: Scripta Nova: Revista Electronica de Geografia y Ciencias Sociales, v.XI, n.245(63), p.1-11. 
Vygotsky, L. (2000). A construção do pensamento e da linguagem. São Paulo: Martins Fontes.

Porcentagem de contribuição de cada autor no manuscrito

Paulo Eduardo Alves Borges da Silva - 70\%

Malena Silva Nunes $-30 \%$ 